Session 2793

\title{
The Synergistic Roles of a Supportive Institutional Environment, Curriculum Development and a Student-friendly Business Incubator in Developing Engineering Students with an Entrepreneurial Orientation
}

\author{
Keith Sheppard*, Gina Boesch** and John Mihalasky* \\ *Charles V. Schaefer, Jr. School of Engineering \\ ** Stevens Technology Ventures Incubator \\ Stevens Institute of Technology \\ Hoboken, New Jersey, 07030
}

\begin{abstract}
Stevens Institute of Technology has been creating an educational environment that has been named Technogenesis ${ }^{\mathrm{TM}}$ to capture an orientation towards entrepreneurship that permeates the broader institutional mindset, from undergraduate programs through to graduate programs and faculty scholarship. Technogenesis has been embraced as a strategic direction for the Institute through retreats, group discussions and forums over a number of years involving faculty, trustees, administrators and students.
\end{abstract}

Curriculum development has seen the introduction of entrepreneurship elements into the undergraduate engineering core, mostly through the eight-semester design sequence, as well as elective coursework and seminars. Students are encouraged to work with faculty on projects that have the potential to spawn intellectual property as well as advance knowledge for dissemination in the traditional manner. The infrastructure is provided to assist and encourage faculty and students to move their intellectual property through to commercialization in cooperation with industry or through a startup venture in the Stevens Technology Ventures Incubator.

These elements taken together are synergistically leading to a campus-wide excitement towards entrepreneurship both in educating students for a world in which such an orientation is becoming a key success factor and providing an additional path for faculty to contribute to their own success and that of the Institute.

\section{Introduction}

There is a significant trend nationally to develop a more entrepreneurial orientation in engineering students. This has come about primarily because the environment into which our students are and will graduate has undergone a profound change in recent years. Jobs are being created in small companies and start-up ventures. This has been paralleled by the fact that major 
corporations have been forced by intense global competition to fundamentally change their structures to become leaner and more agile. This has led to increased use of contract professionals, more emphasis on flexible multidisciplinary teams (in many cases operating internationally) and corporations taking a different stance to new product development. The latter includes buying in new technology once it has been proven rather than developing inhouse. It also includes promotion of intrapreneurship, including spinning off successful internal ventures to maximize value. For engineering graduates entering this environment, an entrepreneurial orientation and associated knowledge and skills will be a key career enabler.

\section{Development of an institutional culture to foster entrepreneurship}

In response to recognition of the changing business environment, which fundamentally affects our various stakeholders, Stevens has engaged in a sea change in its culture to promote an orientation to a more entrepreneurial institutional mindset, from undergraduate programs through to graduate programs and faculty scholarship. This has been given the name Technogenesis ${ }^{\mathrm{TM}}$ and is officially defined as "the educational frontier wherein faculty, students and colleagues from industry jointly nurture the process of conception, design, and marketplace realization of technology".

As noted by Stevens Institute historian Dr. Geoffrey Clark, "it (Techogenesis) was inspired by the engineer-entrepreneurs of the family of John Stevens that pioneered the first successful American railroad, promoted establishment of the U.S. patent office to protect intellectual property, and founded the Institute to create "captains of industry." So in this respect we are seeing a reaffirmation of the original core values of the founders.

Technogenesis represents a strategic move that came as a result of a series of retreats and forums that started in 1997 and continue. They have involved faculty, staff, trustees, students as well as representatives of business, industry and government.

The outcome of these deliberations was formation of a Technogenesis Task Force to determination how best to promote an entrepreneurial culture. The Task Force established a set of objectives, actions, timelines, projected costs and responsibilities. They engaged the Trustees and established a Technogenesis Fund. This has been used to provide seed funds to some 22 faculty in the last two years for entrepreneurial research involving students. The Fund also supports Summer TG scholarships to encourage undergraduates to engage in entrepreneurial research with faculty and with startup companies in the Stevens Technology Ventures Incubator. There were 22 awarded in 2001 and 25 in 2002. An entity named Stevens Technologies Inc. was created to support the commercialization of Stevens' intellectual property and to provide support to faculty and students who wish to start businesses in partnership with Stevens.

\section{Technology Ventures Incubator}

Stevens Technology Ventures Incubator (TVI) was started in 1991 on the campus of the Institute. Its location has helped it become an integral part of campus life as the Technogenesis initiative has progressed, with many students and faculty working with the resident companies. It 
has proven very successful in nurturing startup companies to success and has won several awards. It has assisted 56 resident companies and helped them to raise over $\$ 55 \mathrm{M}$. However, until relatively recently these were companies that came to Stevens rather than being started by Stevens personnel. Since 1998, TVI has sought to be the location of choice for Stevens' own technology transfer initiatives, providing office space, business experience and networking opportunities to start-ups that license and commercialize Stevens' patented technology. In the last four years eight companies have been formed that involve Stevens faculty, in addition several companies have been started by recent graduates during that period.

\section{Impact on the engineering curriculum}

For undergraduate engineering students there are two levels of engagement. There is a base level introduction to entrepreneurship materials in the core curriculum. This is implemented primarily through the core design course sequence that extends through all eight semesters, and through increased focus on project-based learning. The Design Spine includes fundamentals of marketing, finance, business development and project management. A second level provides for students with the interest to supplement the core material with an elective senior year course that focuses on intrapreneurship and entrepreneurship aspects of business. Seminars on Intellectual Property, Venture Funding, etc., are also provided on campus.

The engineering curriculum is illustrated in Figure 1 to highlight the eight-semester Design Spine.

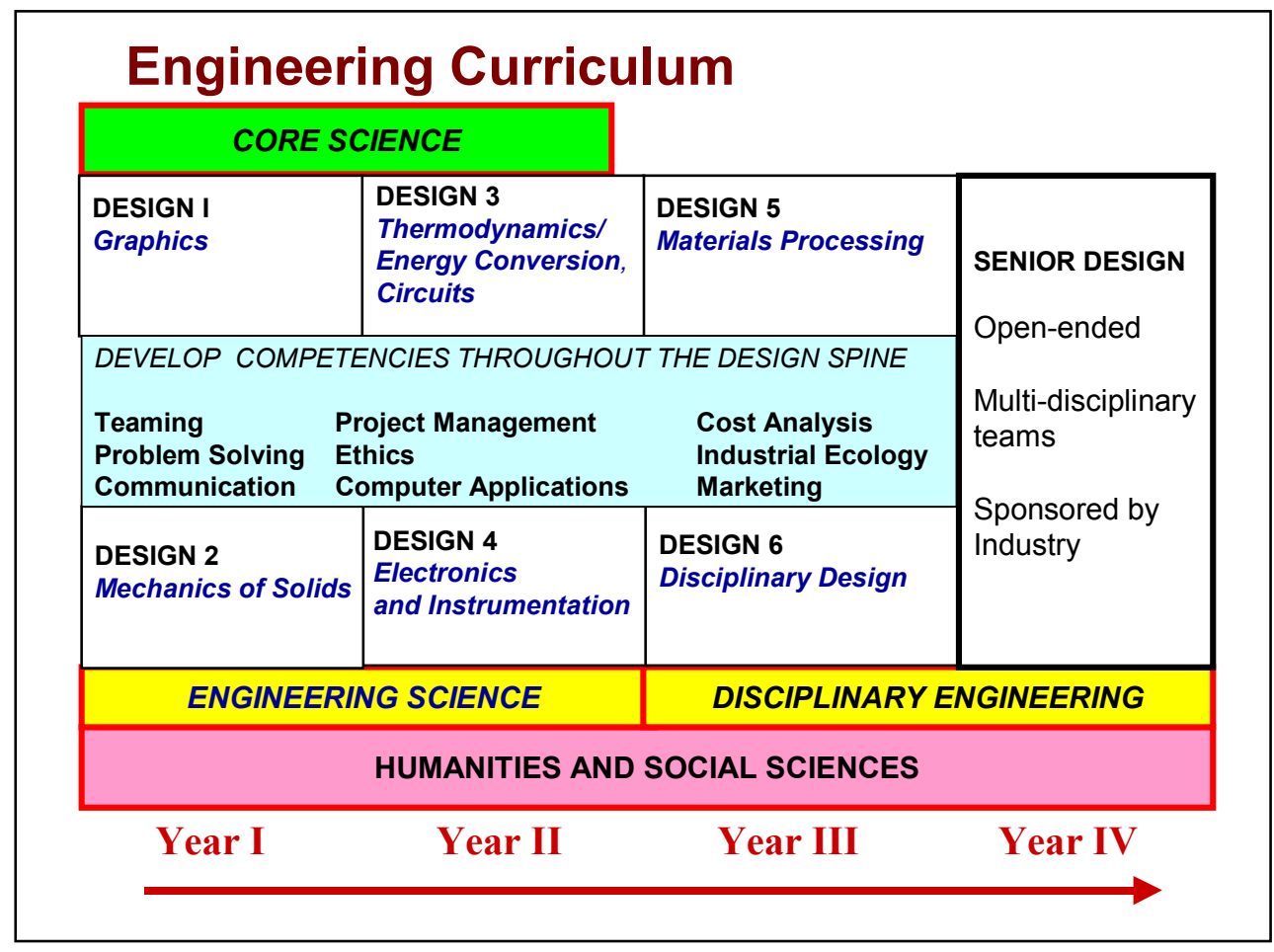

Figure 1 The Stevens Engineering Curriculum 
In Figure 1 the design labs are shown as boxes within which (in italics) are shown the engineering lecture course(s) to which each design lab is associated. Thus, Design 4 includes experiments and design projects that link to and provide context for the concurrent lecture course on Electronics and Instrumentation. The center panel illustrates a range of competencies that are developed primarily through the Design Spine experiences.

\section{Project-Based Learning}

A key pedagogical element of the environment that we are evolving is the permeation of ProjectBased Learning (PBL) through the curriculum. This is a means to foster attributes that are needed for a more entrepreneurial career environment as well as being recognized as a means to improve learning outcomes. PBL encourages self-reliance and innovative thinking and also can contribute significantly to enhancing team skills.

Initial implementation in the core curriculum has been in the freshman year Mechanics of Solids course and in sophomore Probability and Statistics. It has found wide implementation in concentration courses, with for example, more than 50\% of the required Mechanical Engineering courses being taught by PBL. Support for implementing Technogenesis in the undergraduate curriculum, including support of faculty to develop PBL, has in part come through a $\$ 1.3 \mathrm{M}$ grant from the New Jersey Commission on Higher Education (NJCHE), under its Workforce Excellence Program. The other major component, funded by the NJCHE grant, is the Innovation Center discussed below.

\section{Engagement in Research with an Entrepreneurial Orientation}

Students are encouraged to engage in faculty research projects that have the potential to generate intellectual property in addition to the traditional goal of publication of new knowledge.

One route to encourage this has been through Undergraduate Technogenesis Summer Scholarships. As example, more than 65 students applied for these high-qualification, projectbased summer study scholarships in 2001; 23 students were approved for this first series of awards, disbursed for that summer. Scholarship projects included work in the fields of computer cryptography, arsenic removal from drinking water, wireless networking, and non-thermal plasma technology. A number of the awards were to students who worked with start-up ventures created by faculty in the Stevens Technology Ventures Incubator. In 2002 an additional 25 students were funded. In addition to Stevens-funded summer scholarships, the National Science Foundation CSEMS Program ${ }^{1}$ has funded approximately 40 academic year scholarships per year in the last two years. This program is intended to help mostly financially disadvantaged students to complete technical degree programs. At Stevens this program is coupled to Technogenesis to encourage participation in the latter as an enabler of graduation and career success.

\footnotetext{
${ }^{1}$ Supported by the National Science Foundation under Grant No. 998720 Proceedings of the 2003 American Society of Engineering Education Annual Conference and Exposition Copyright (C) 2003, American Society for Engineering Education
} 


\section{Product Innovation Center}

Students are able to make use of the equipment and software tools provided by the Product Innovation and Realization Center to move from the conceptual phase of their projects through to prototype. This is a key step on the path to potential commercialization. The Center comprises an open plan, high-bay approx. 4000sq. $\mathrm{ft}$ area containing rapid prototyping via $\mathrm{CNC}$ machines, 3-D printing directly from graphics software and also electronic prototyping to create circuit boards. The Center also has a range of mechanical and electronic test equipment. Industrial size $\mathrm{CNC}$, electro-discharge machining and an injection molder are hosted in the facility. The Center is supported by technicians with machining and electronics expertise and is under the management of a faculty member. Software tools for mechanical (SolidWorks, ProEngineer) and electronic design (Protel) also are available in support of prototype design.

The further development of commercially attractive ideas can take place through the Stevens Technology Ventures Incubator located on the campus. The Incubator not only provides a physical location for new ventures and access to Stevens resources, it also provides support services, including favorable connections to legal, accounting and financing resources as well as. It is telling that some $80 \%$ of Incubator companies have had Stevens students work with them on projects. A number of successful start-ups have been created in the Incubator by Stevens faculty in recent years, and several by recent Stevens graduates.

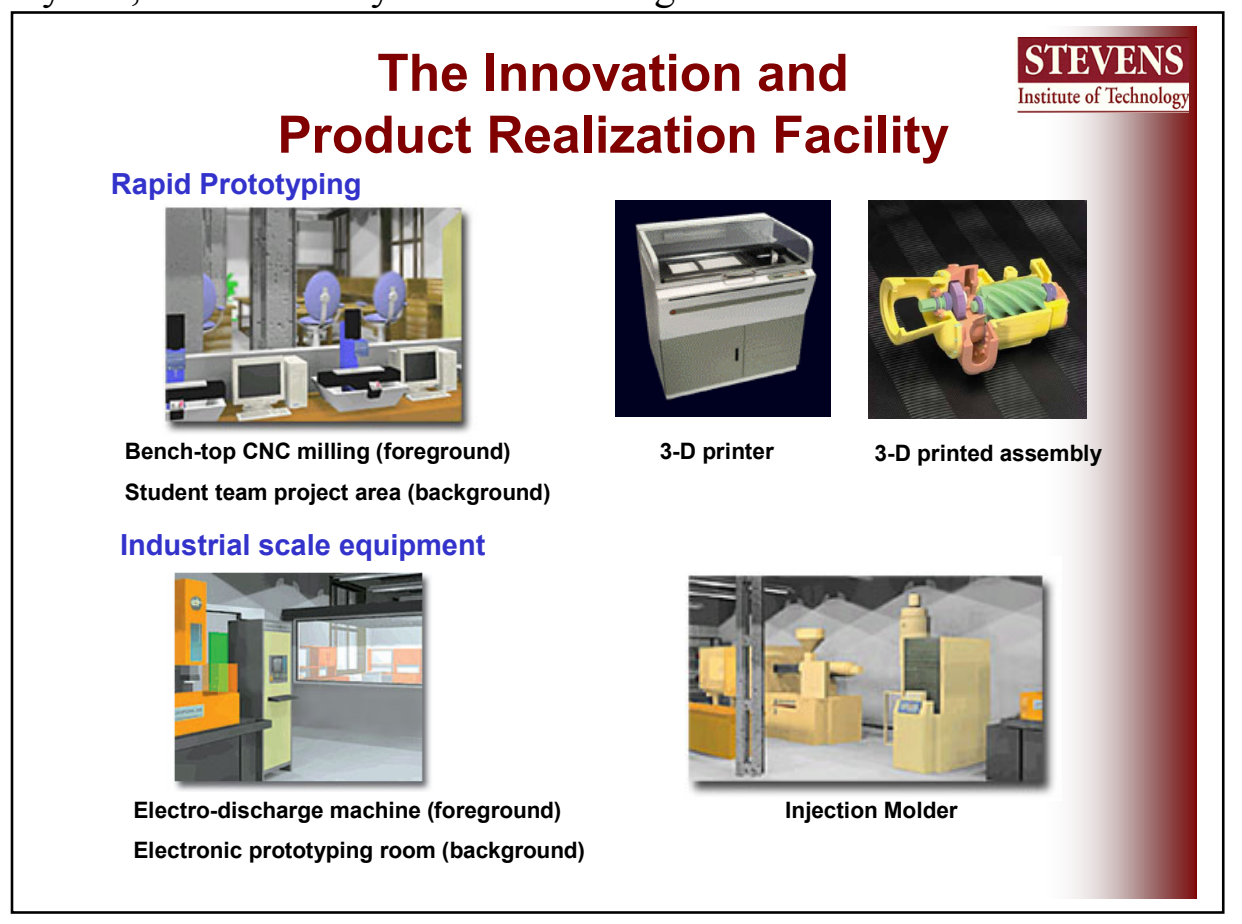

\section{Concluding Summary}

Stevens Institute has made good progress on a strategic orientation of the university's culture towards one that is entrepreneurial on many levels and facets of the academic enterprise, 
including faculty research and both undergraduate and graduate education. The impact on the undergraduate curriculum is illustrated in Fig. 2.

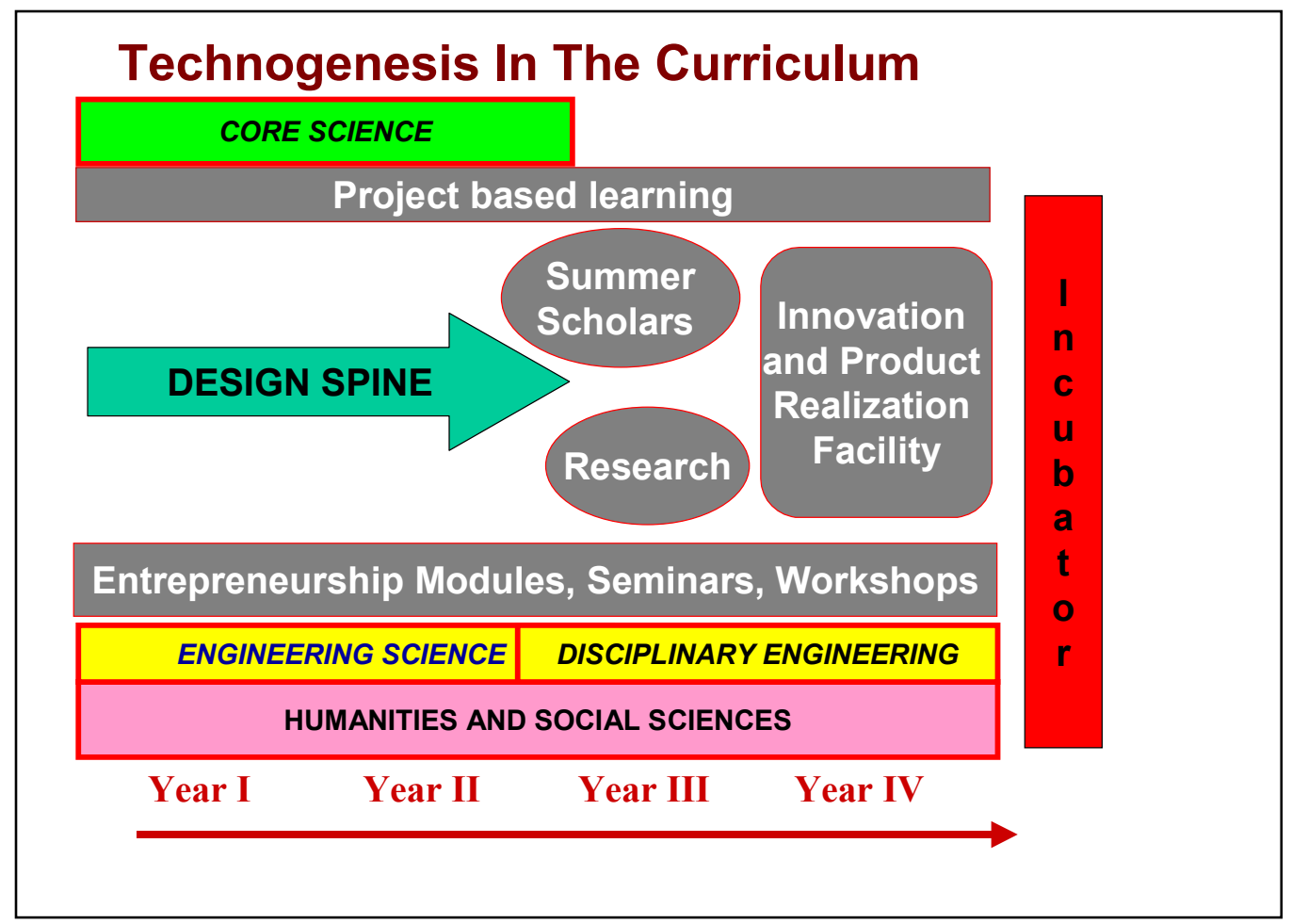

\section{Figure 2 Entrepreneurship elements of the undergraduate engineering curriculum}

\section{Biographical Information}

KEITH SHEPPARD is a Professor of Materials Engineering and Associate Dean of Engineering. He earned the B.Sc. from the University of Leeds, England and Ph.D. from the University of Birmingham, England, both in metallurgy. As Associate Dean, Sheppard is primarily responsible for undergraduate programs.

GINA BOESCH is the Director of Technology Ventures Incubator received her M.S. degree in Management from Stevens Institute of Technology. She has been Executive Director of TVI since 1991, responsible for strategic, tactical and operational administration. Boesch is a member of the National Business Incubator Association, the New Jersey Technology Council, and is Chair of the New Jersey Business Incubation Network.

JOHN MIHALASKY is Exemplary Service Professor of Engineering Management. He earned the Ph.D. in Business Education form Columbia. He also holds Master's degrees in Industrial Engineering, Management Engineering and Business Administration. He is a founding member of ASEM, a Fellow of ASQ and a Fellow of SAM. He directs the Engineering Management undergraduate program at Stevens. 